\title{
Application of Local Hyaluronic Acid Injection in Transanal Minimally Invasive Surgery for Anterior Rectal GIST
}

\author{
Hidekazu Takahashi, MD, PhD ${ }^{\mathbf{1}}$, Ichiro Takemasa, MD, PhD, FACS ${ }^{2}$, Norikatsu Miyoshi, MD, PhD, FACS ${ }^{1}$, \\ Mamoru Uemura, MD, PhD, FACS ${ }^{1}$, Hirofumi Yamamoto, MD, PhD $^{1}$, Tsunekazu Mizushima, MD, PhD $^{1}$, \\ Yuichiro Doki, MD, $\mathbf{P h D}^{1}$, and Hidetoshi Eguchi, $\mathbf{M D}, \mathbf{P h D}^{1}$ \\ ${ }^{1}$ Department of Gastroenterological Surgery, Graduate School of Medicine, Osaka University, Suita, Osaka, Japan; \\ ${ }^{2}$ Department of Surgery, Surgical Oncology and Science, Sapporo Medical University, Sapporo, Japan
}

\section{MULTIMEDIA ARTICLE}

Organ-preserving resection of rectal gastrointestinal stromal tumors (GISTs) is particularly challenging due to the anatomic constraints of close contacts with surrounding organs. Transanal minimally invasive surgery (TAMIS) with high-resolution imaging is suitable for acquiring better visualization of target lesions, ${ }^{1,2}$ but TAMIS for anterior rectal GISTs is technically challenging.

To make the most of the magnifying effect of endoscopic surgery, we applied local hyaluronic acid injection, which is used in endoscopic submucosal dissection ${ }^{3,4}$ to select the layer to be dissected for fine manipulation.

This video shows TAMIS in a 70-year-old male with a rectal GIST located at the anterior wall $3 \mathrm{~cm}$ from the anal verge. Under general anesthesia, the patient was set in the jackknife position. The GelPoint Path (Applied Medical, Inc., Rancho Santa Margarita, CA) was inserted and pneumorectum started as is standard. For careful layer selection, hyaluronic acid (MucoUp, Boston Scientific Corp, Tokyo, Japan) containing indigo carmine was locally injected into the resected layer using an injection needle (MAJ-72, Olympus Corp, Tokyo, Japan) in a prototype

Supplementary Information The online version contains supplementary material available at. https://doi.org/10.1245/s10434020-09569-1.

(C) Society of Surgical Oncology 2021

First Received: 3 June 2020

Accepted: 26 December 2020;

Published Online: 16 January 2021

H. Takahashi, MD, PhD

e-mail: htakahashi@gesurg.med.osaka-u.ac.jp grasper. After complete removal of the tumor, the defect was closed with a barbed suture. The patient was discharged on postoperative Day 3.

Hyaluronic acid does not stimulate tumor growth. ${ }^{5}$ Our procedure may be a potentially useful option for local excision of lesions in technically challenging positions using TAMIS.

FUNDING This study was not supported by any grants. This study has not been presented at any meeting.

\section{REFERENCES}

1. Pintor-Tortolero J, Garcia JC, Cantero R. Transanal minimally invasive surgery for rectal GIST. Tech Coloproctol. 2016;20(5):321-2.

2. deBeche-Adams T, Nassif G. Transanal minimally invasive surgery. Clin Colon Rectal Surg. 2015;28:176-80.

3. Yamamoto H, Kawata H, Sunada K, et al. Success rate of curative endoscopic mucosal resection with circumferential mucosal incision assisted by submucosal injection of sodium hyaluronate. Gastrointest Endosc. 2002;56:507-12.

4. Hirasaki S, Kozu T, Yamamoto H, et al. Usefulness and safety of $0.4 \%$ sodium hyaluronate solution as a submucosal fluid "cushion" for endoscopic resection of colorectal mucosal neoplasms: a prospective multi-center open-label trial. BMC Gastroenterol. 2009;9:1 https://doi.org/10.1186/1471-230X-9-1.

5. Sohn DK, Chang HJ, Choi HS, et al. Does hyaluronic acid stimulate tumor growth after endoscopic mucosal resection? J Gastroenterol Hepatol. 2008;23:1204-7.

Publisher's Note Springer Nature remains neutral with regard to jurisdictional claims in published maps and institutional affiliations. 